\title{
Quantitative Analysis of Plasmonic Metal Oxide Nanocrystal Ensembles Reveals the Influence of Dopant Selection on Intrinsic Optoelectronic Properties
}

\author{
Bharat Tandon ${ }^{\dagger}$, Stephen L. Gibbs ${ }^{\dagger}$, Benjamin Z. Zydlewski, Delia J. Milliron* \\ McKetta Department of Chemical Engineering, University of Texas at Austin, \\ Austin, Texas 78712-1589, United States \\ $\dagger^{\dagger}$ Authors contributed equally \\ *corresponding author \\ Email: milliron@che.utexas.edu
}




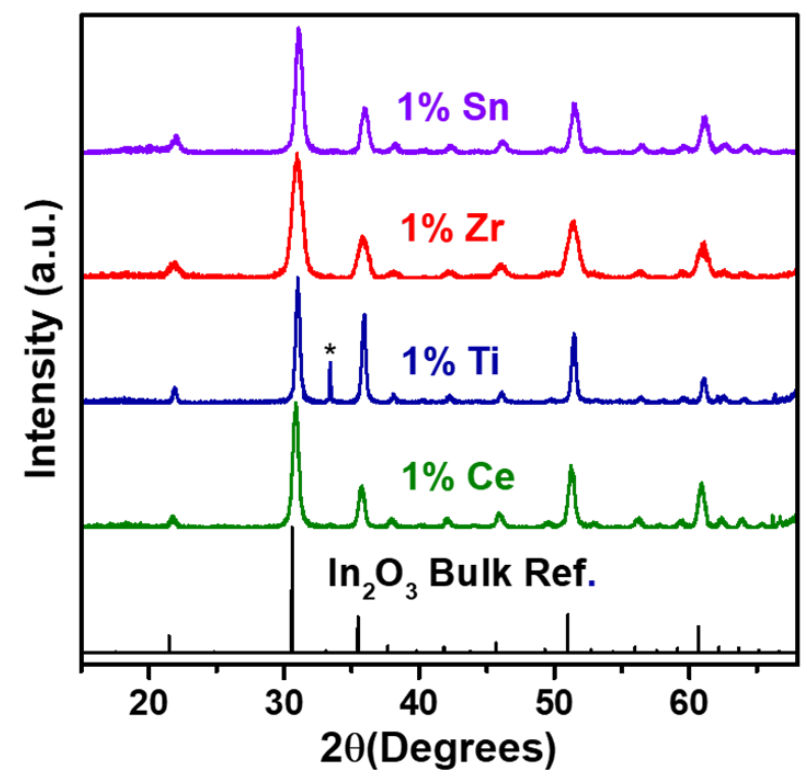

Figure S1: X-ray diffraction patterns of different $1 \%$ doped $\operatorname{In}_{2} \mathrm{O}_{3}$ NCs showing phase pure NCs exhibiting the same cubic bixbyite structure as the bulk reference (JCPDS 88-2160). The diffraction peaks marked with * belong to the Si substrate.

Table ST1: Comparison of sizes of different doped $\operatorname{In}_{2} \mathrm{O}_{3}$ NCs from STEM and that calculated from Scherrer equation using the XRD diffraction data.

\begin{tabular}{|c|c|c|}
\hline Sample Composition & STEM Radius (nm) & $\begin{array}{c}\text { Scherrer Radius from } \\
\text { XRD (nm) }\end{array}$ \\
\hline $1 \% \mathrm{Zr}$ & $5.0 \pm 0.4$ & 5.4 \\
\hline $1 \% \mathrm{Sn}$ & $7.7 \pm 0.4$ & 7.8 \\
\hline $1 \% \mathrm{Ce}$ & $9.1 \pm 1.1$ & 9.0 \\
\hline $1 \% \mathrm{Ti}$ & $12.5 \pm 1.2$ & 12.4 \\
\hline
\end{tabular}



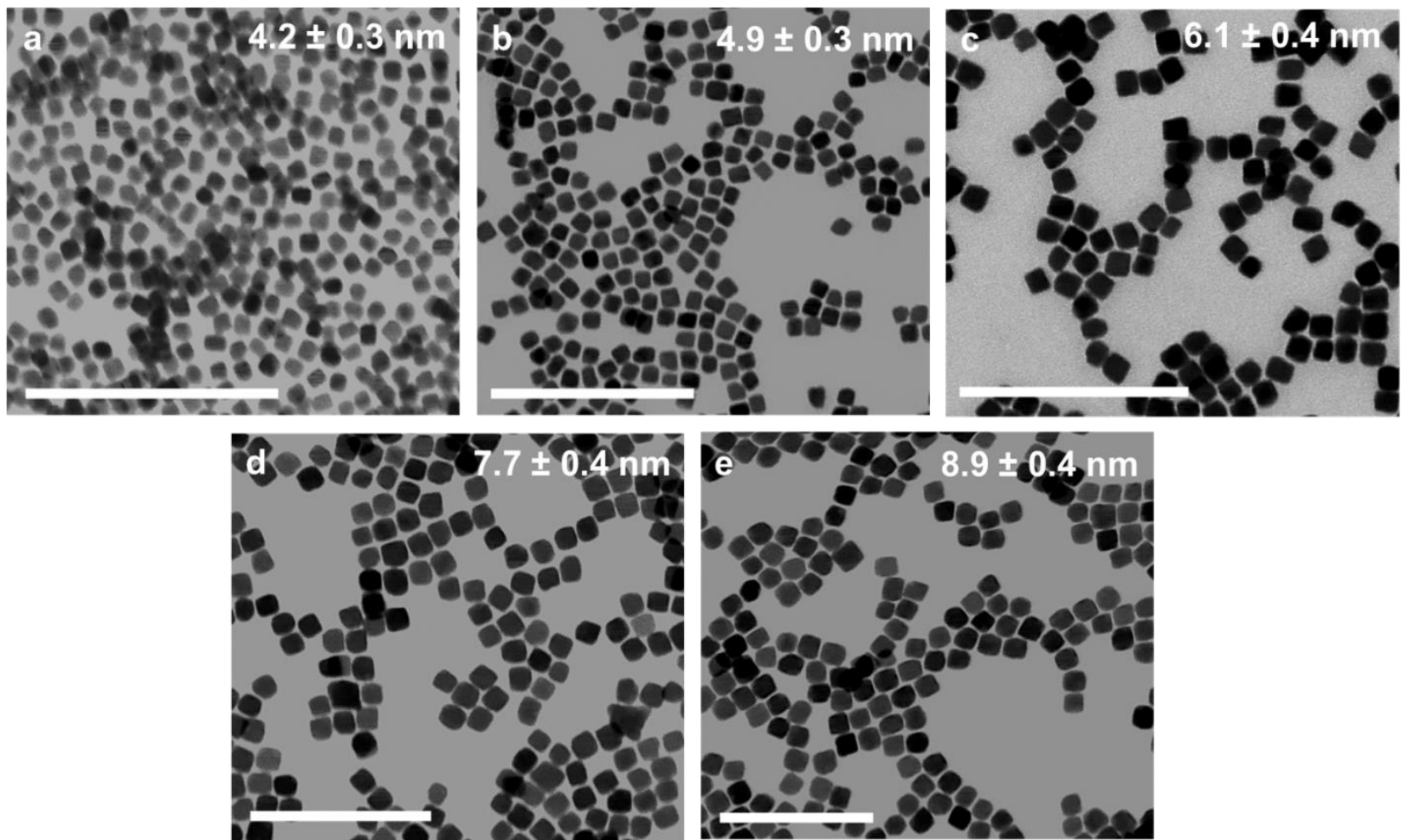

Figure S2: STEM images of $1 \% \mathrm{Sn}$-doped $\mathrm{In}_{2} \mathrm{O}_{3} \mathrm{NCs}$ with different radius. All scale bars are 100 nm.
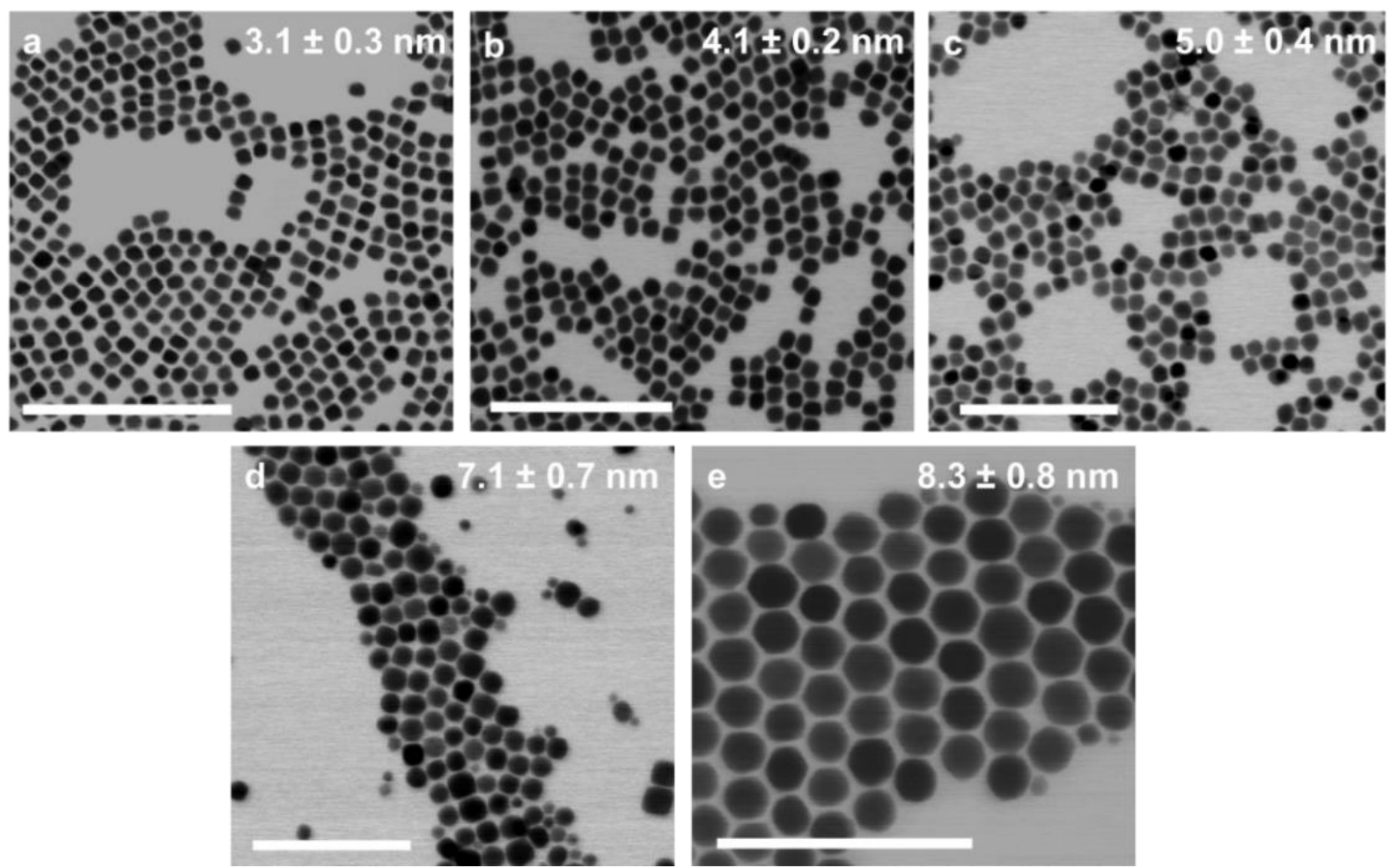

Figure S3: STEM images of $1 \% \mathrm{Zr}$-doped $\operatorname{In}_{2} \mathrm{O}_{3} \mathrm{NCs}$ with different radius. All scale bars are 100 nm. 

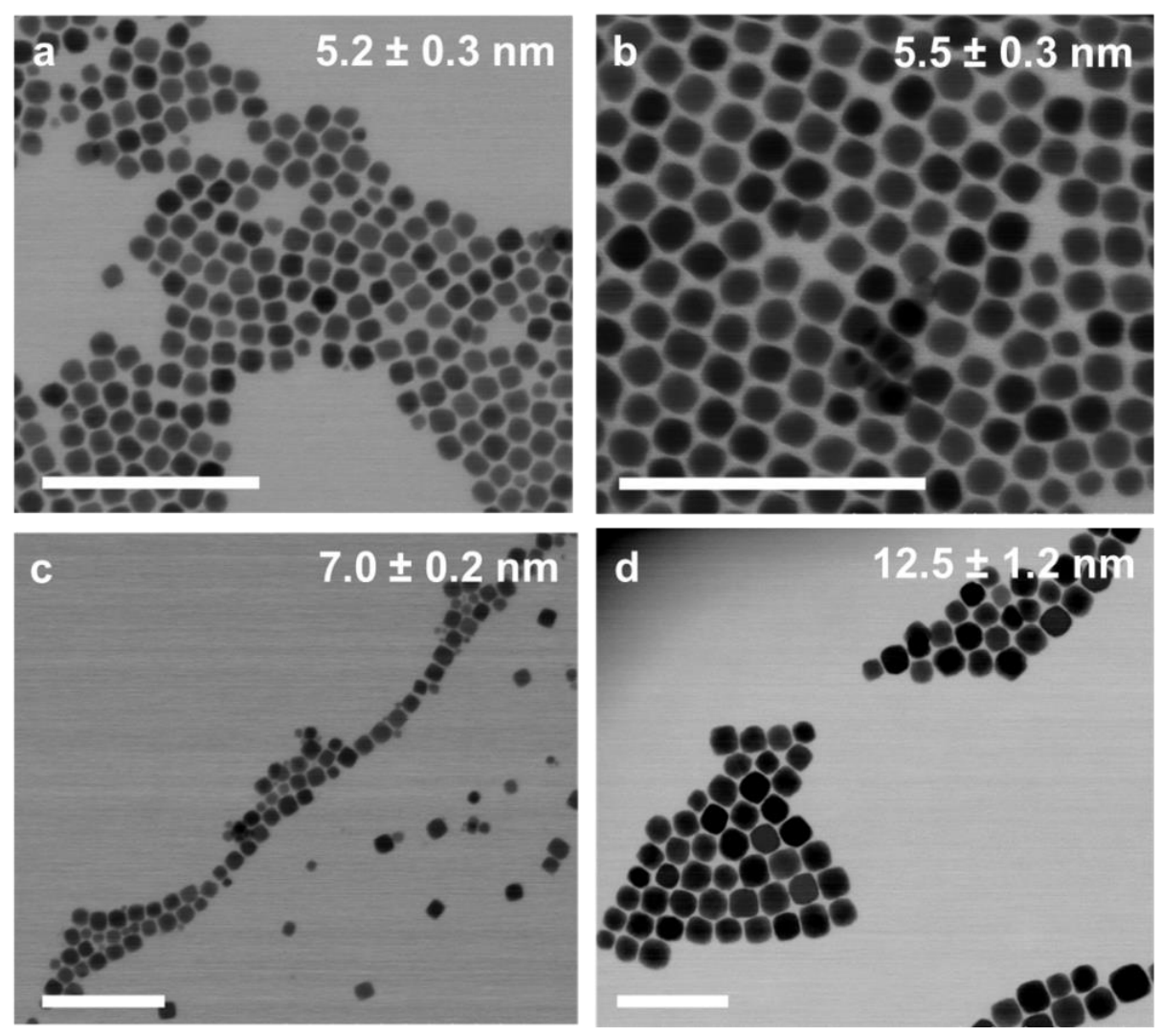

Figure S4: STEM images of $1 \%$ Ti-doped $\operatorname{In}_{2} \mathrm{O}_{3} \mathrm{NCs}$ with different radius. All scale bars are 100 nm.
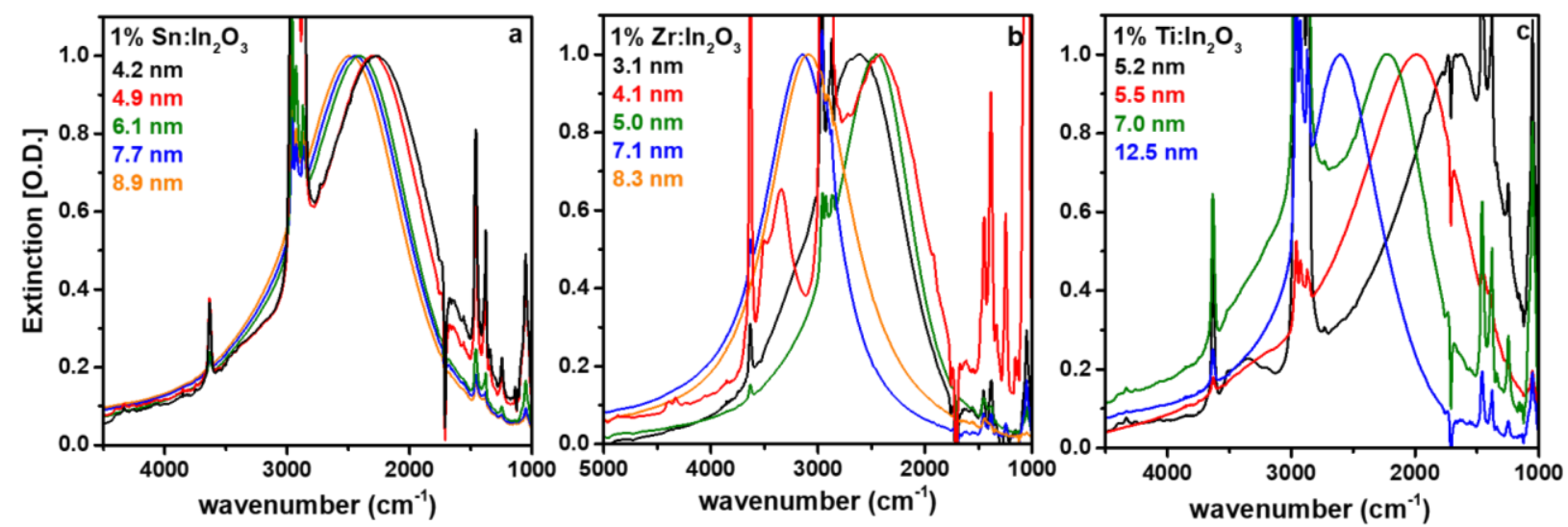

Figure S5: Normalized extinction spectra, for (a) $1 \% \mathrm{Sn}_{\mathrm{In}} \mathrm{I}_{2} \mathrm{O}_{3} \mathrm{NCs}$ (b) $1 \% \mathrm{Zr}: \mathrm{In}_{2} \mathrm{O}_{3} \mathrm{NCs}$ and (c) $1 \% \mathrm{Ti}: \mathrm{In}_{2} \mathrm{O}_{3} \mathrm{NCs}$ of increasing radius. 

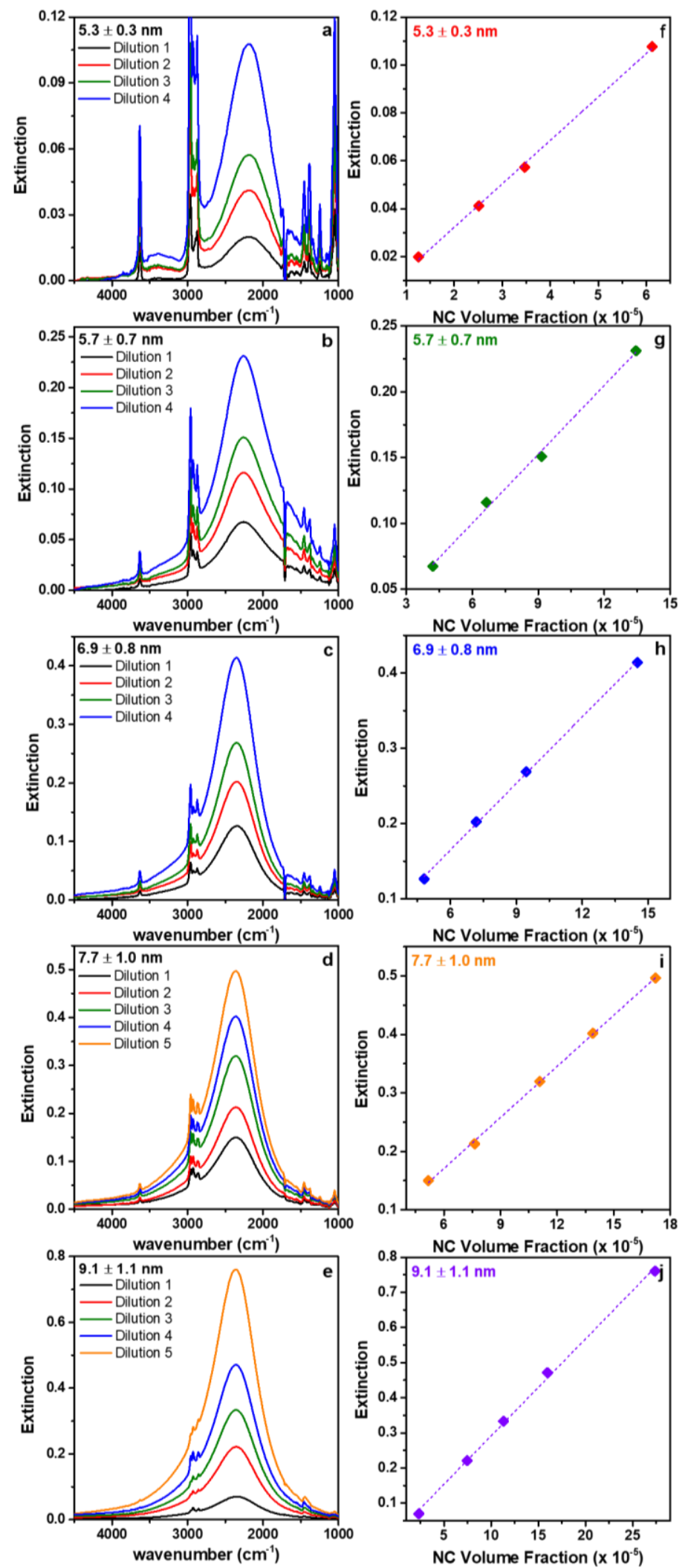

Figure S6: (a-e) Extinction spectra of different dilutions (f-j) Beer-Lambert's curves for 1\% $\mathrm{Ce}: \mathrm{In}_{2} \mathrm{O}_{3} \mathrm{NCs}$ with increasing radius. 

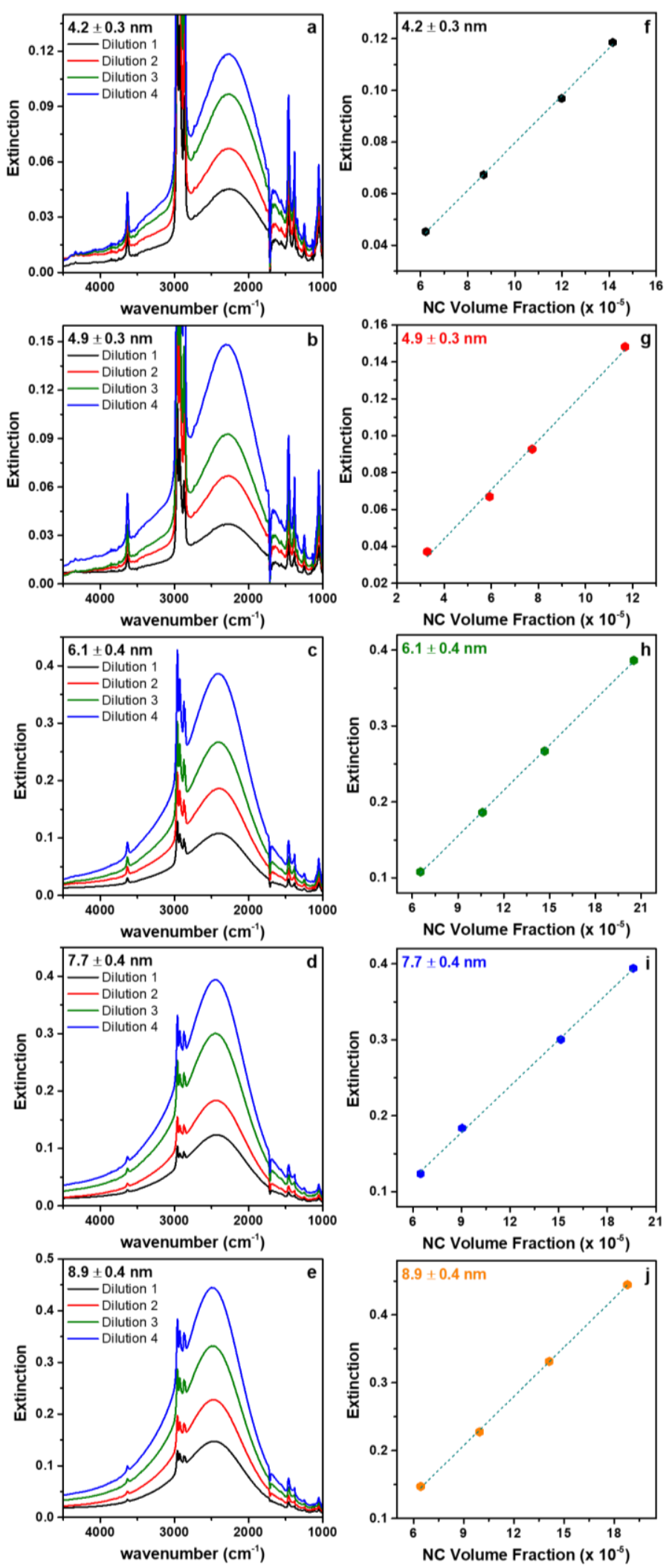

Figure S7: (a-e) Extinction spectra of different dilutions (f-j) Beer-Lambert's curves for 1\% $\mathrm{Sn}: \mathrm{In}_{2} \mathrm{O}_{3} \mathrm{NCs}$ with increasing radius. 

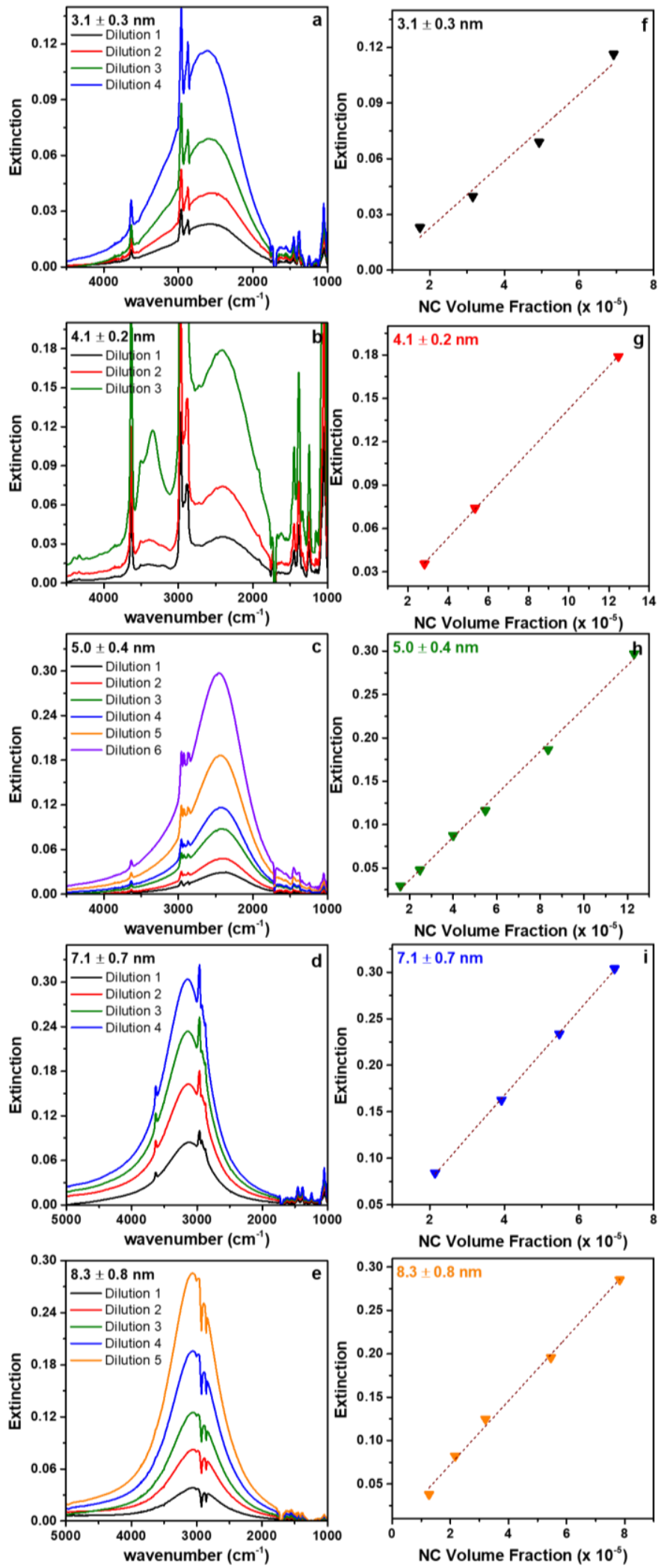

Figure S8: (a-e) Extinction spectra of different dilutions (f-j) Beer-Lambert's curves for 1\% $\mathrm{Zr}: \mathrm{In}_{2} \mathrm{O}_{3} \mathrm{NCs}$ with increasing radius. 

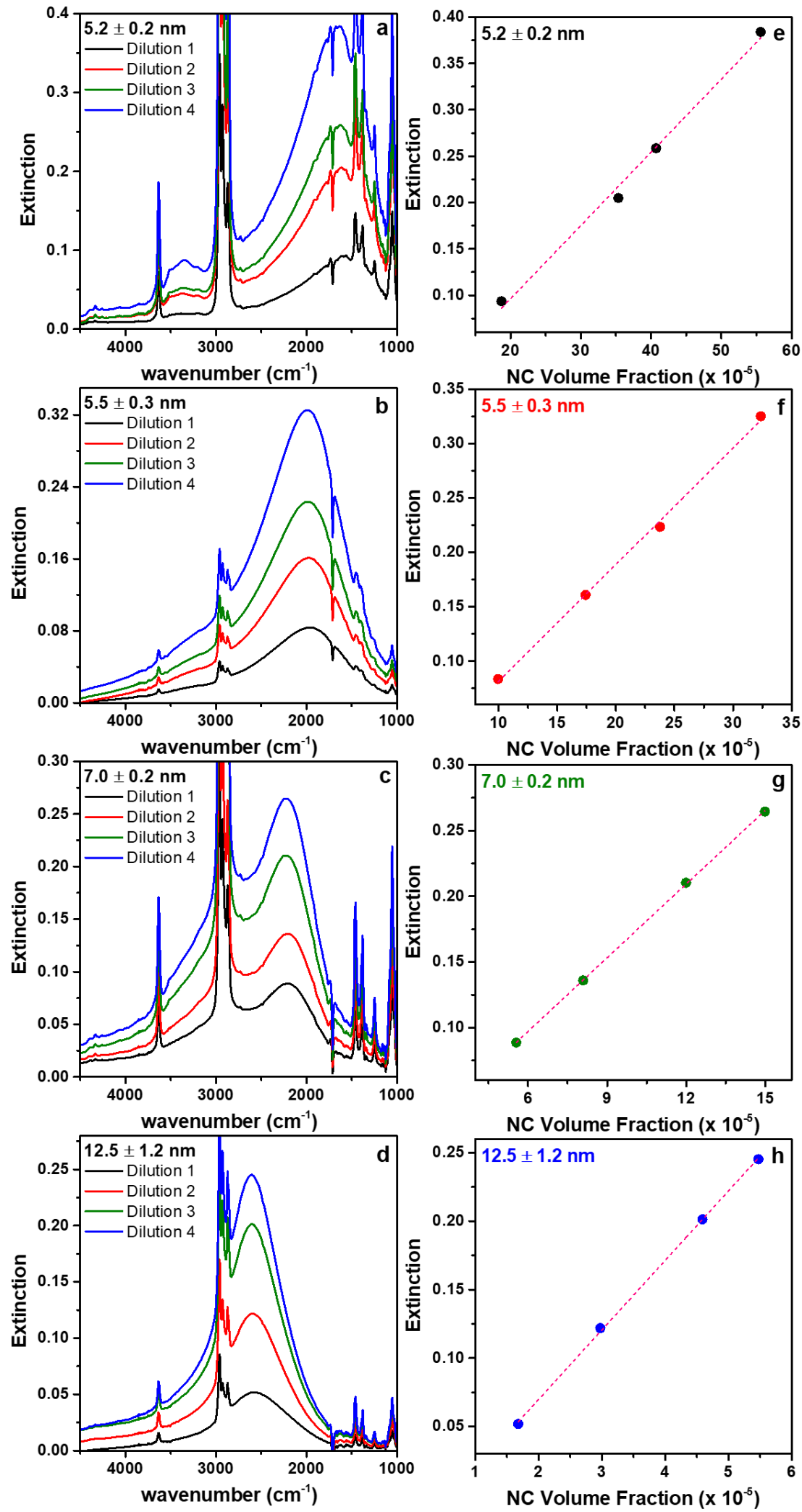

Figure S9: (a-e) Extinction spectra of different dilutions (f-j) Beer-Lambert's curves for 1\% Ti: $\operatorname{In}_{2} \mathrm{O}_{3} \mathrm{NCs}$ with increasing radius. 

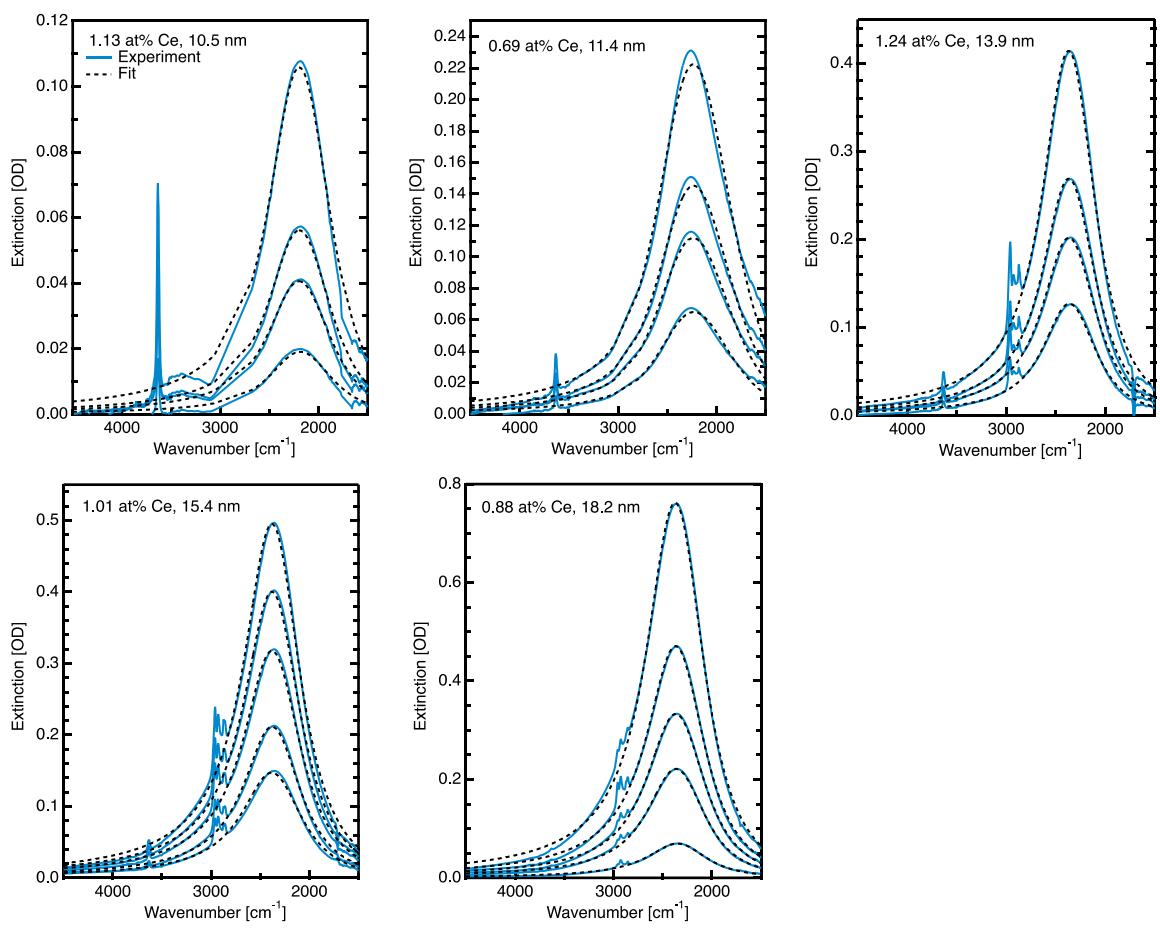

Figure S10: Experimental extinction spectra (blue solid lines) and HEDA fits (black dashed lines) for all samples and dilutions of the Ce-doped $\operatorname{In}_{2} \mathrm{O}_{3}$ series.
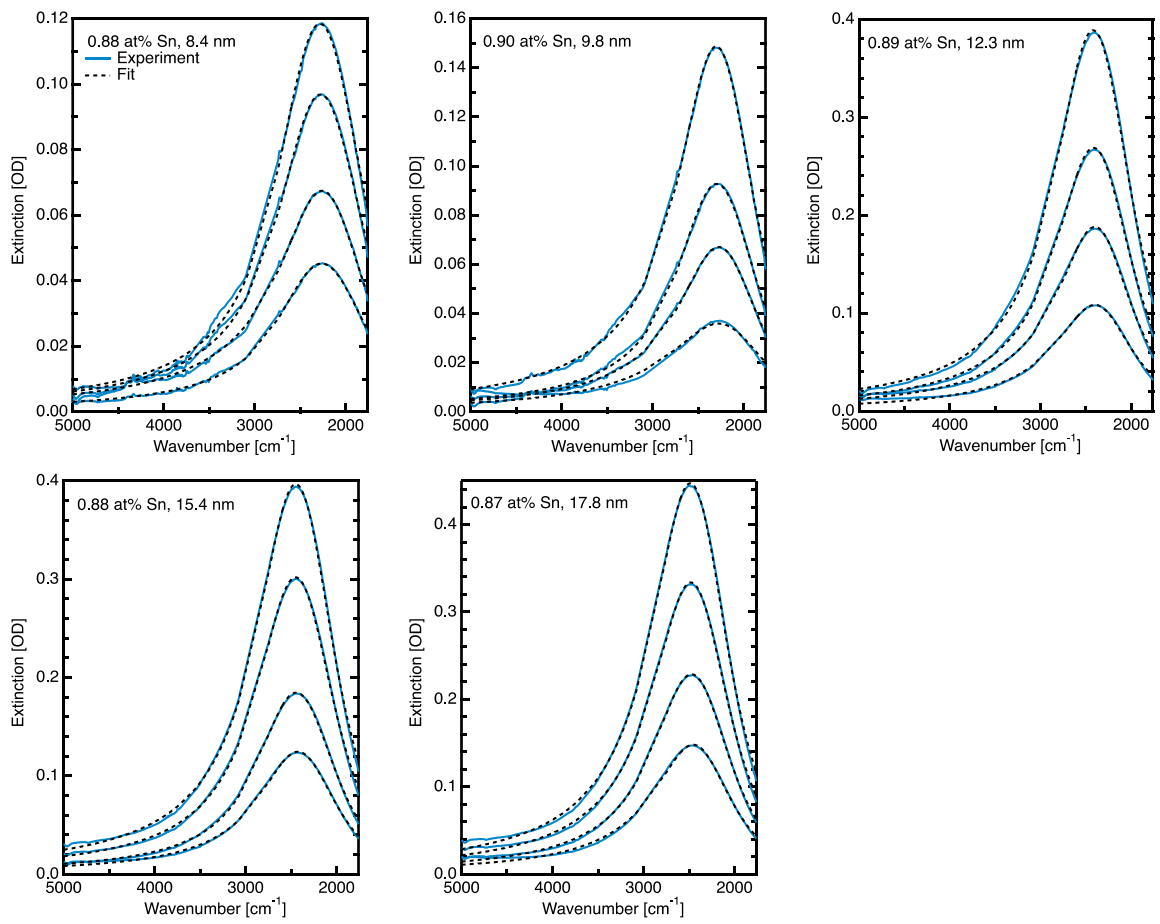

Figure S11: Experimental extinction spectra (blue solid lines) and HEDA fits (black dashed lines) for all samples and dilutions of the $\mathrm{Sn}$-doped $\mathrm{In}_{2} \mathrm{O}_{3}$ series. 

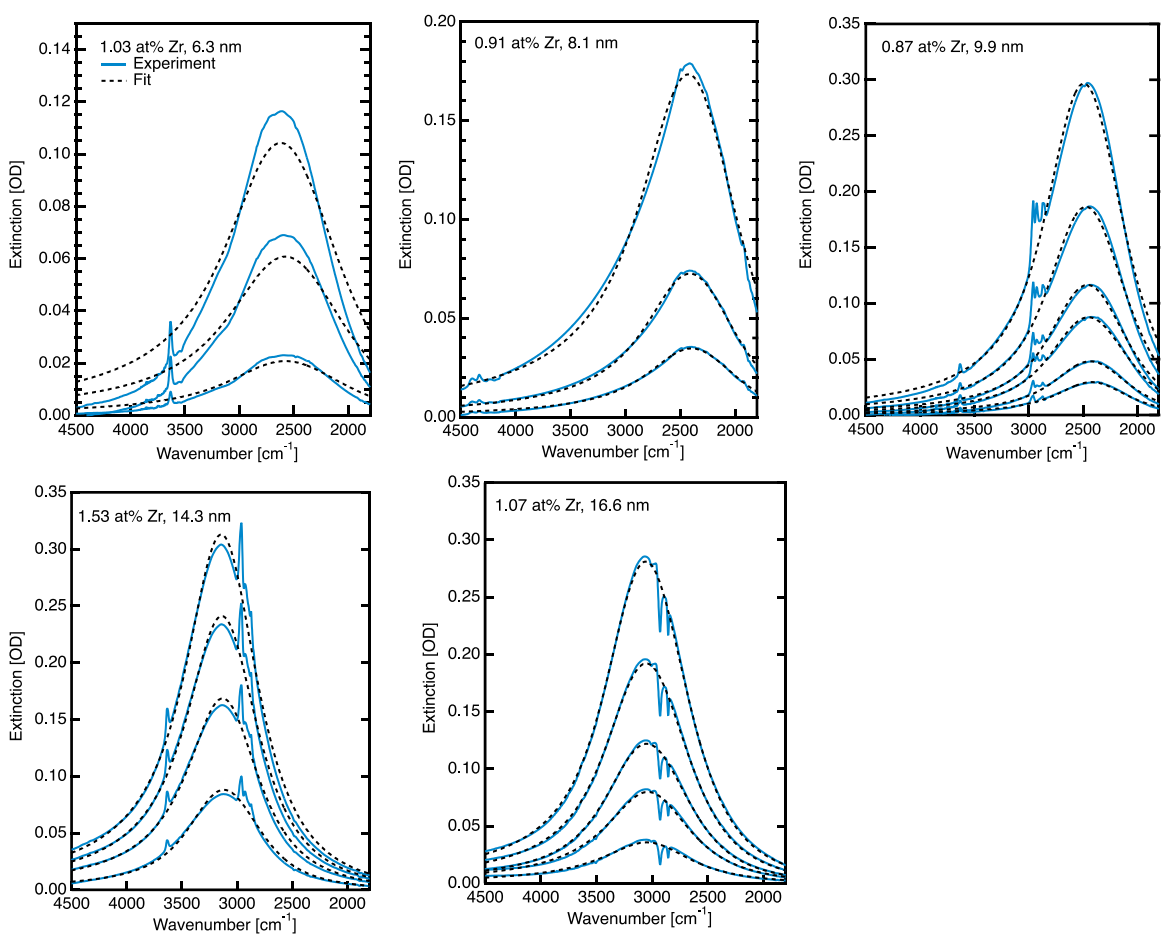

Figure S12: Experimental extinction spectra (blue solid lines) and HEDA fits (black dashed lines) for all samples and dilutions of the $\mathrm{Zr}$-doped $\mathrm{In}_{2} \mathrm{O}_{3}$ series.
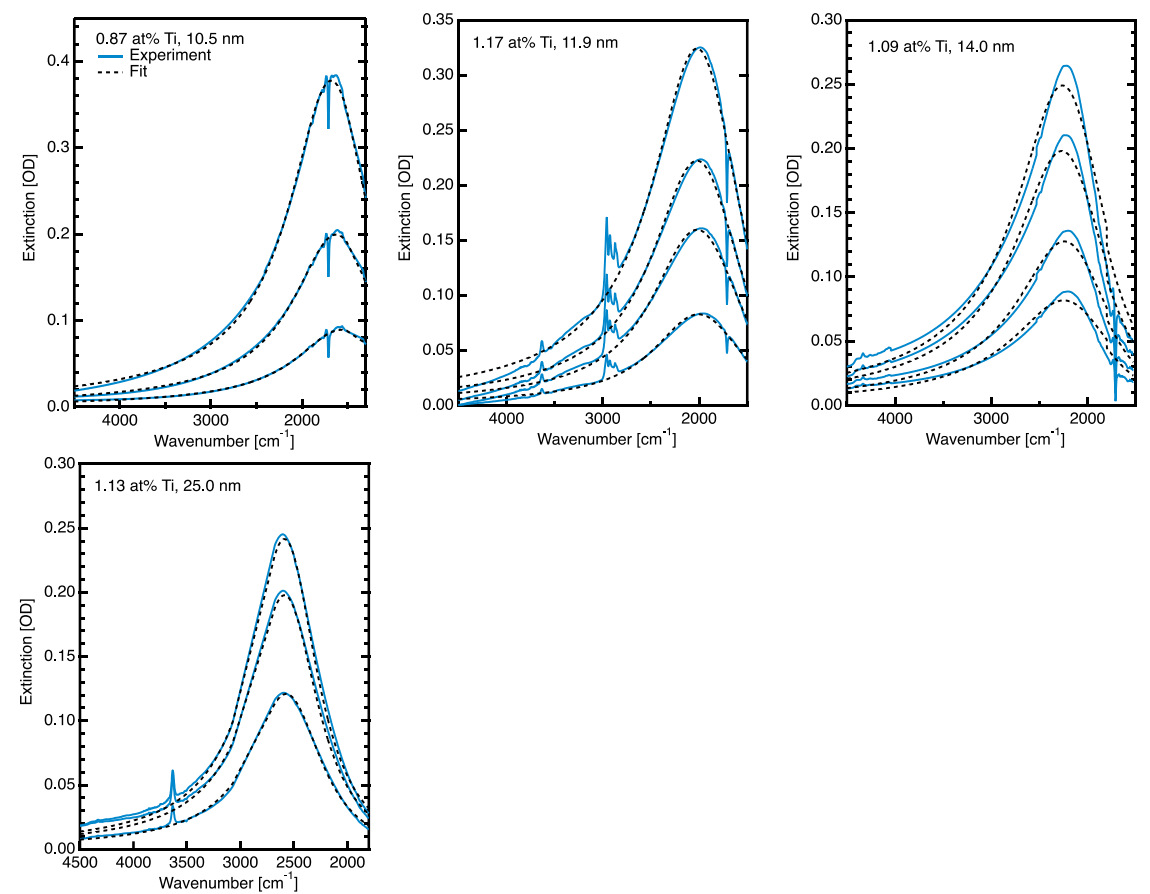

Figure S13: Experimental extinction spectra (blue solid lines) and HEDA fits (black dashed lines) for all samples and dilutions of the Ti-doped $\mathrm{In}_{2} \mathrm{O}_{3}$ series. 